\title{
El doble papel de la Administración Pública en la empresa mixta local
}

\author{
Luis F. Prieto González \\ Doctor en Derecho \\ Secretario General del Ayuntamiento de Güimar \\ Francisco L. Hernández González \\ Doctor en Derecho \\ Profesor de la Universidad de La Laguna
}

Sumario: I. LA SOCIEDAD DE ECONOMIA MIXTA LOCAL EN EL MARCO DE LA MODERNA ADMINISTRACIÓN ECONÓMICA. II. LA EMPRESA MIXTA LOCAL EN LA LEGISLACIÓN ESPAÑOLA: 2.1. Una institución a medio camino entre los Derechos administrativo y mercantil; 2.2. La nueva configuración constitucional de la empresa mixta local: empresas de mercado y empresas de servicio público. III. EL CARÁCTER INSTRUMENTAL DE LA EMPRESA MIXTA. IV. EL CARÁCTER BIFRONTE DE LA ENTIDAD LOCAL EN LA SOCIEDAD DE ECONOMIA MIXTA. V. LA ESPECIAL POSICIÓN DEL SOCIO PÚBLICO: 5.1. La tutela del interés público como determinante de la incorporación de especialidades al régimen mercantil; 5.2. El equilibrio interno de la sociedad. VI. LA ENTIDAD LOCAL EN CUANTO PODER PÚBLICO: EL CONTROL PÚBLICO DE LAS EMPRESAS MIXTAS: 6.1. Fundamentos y límites de la potestad de control; 6.2. Las técnicas de fiscalización administrativa: A. Técnicas de control preventivo; B. Técnicas de control de la gestión. VII. BIBLIOGRAFÍA.

\section{LA SOCIEDAD DE ECONOMÍA MIXTA LOCAL EN EL MARCO DE LA MODERNA ADMINISTRACIÓN ECONÓMICA}

La definición de las Sociedades de economía mixta o empresas mixtas locales, como también se las denomina, no ha sido, ni es hoy en día cuestión pacífica, lo que viene imputándose sistemáticamente a su compleja naturaleza jurídica. No obstante, desde un punto de vista meramente organizativo, como tales se vienen identificando diferentes formas societarias de carácter mercantil cuyo capital social sólo parcialmente pertenece a la Administración local y cuya finalidad principal, pero no exclusiva, es la gestión de servicios públicos.

Con más de medio siglo de supervivencia ${ }^{1}$, este tipo de sociedades experimentan, en la actualidad, un extraordinario fenómeno de crecimiento

1 Prescindiendo de antecedentes previos no muy precisos, la primera referencia clara a las sociedades 
consecuencia de su especial idoneidad para financiar y gestionar servicios y prestaciones públicas de contenido económico. Además, esta singular estructura juridica que es la empresa mixta, responde adecuadamente al vigente modelo de Administración económica, caracterizada por la falta de capacidad inversora del sector público y el desarrollo de una mueva dinámica de relaciones intersectoriales donde la colaboración entre capital público y privado, la participación y la corresponsabilidad de todos los agentes implicados en la consecución de los objetivos sociales constituyen los ejes fundamentales ${ }^{2}$.

En este marco de referencia, las ventajas que ofrece la gestión mixta en forma societaria prevalecen sobre sus posibles inconvenientes ${ }^{3}$ : en primer lugar, por su capacidad integradora, permitiendo el concurso entre capitales públicos y privados y la colaboración permanente en la consecución de las finalidades de interés general; $y$, en segundo lugar, por su propia configuración jurídica como entidad mercantil, que conlleva la aplicación de técnicas empresariales a la gestión de los recursos públicos, convirtiéndola en un instrumento extraordinariamente ágil y flexible para la gestión de las actividades y servicios locales de carácter económico.

\section{LA EMPRESA MIXTA LOCAL EN LA LEGISLACIÓN ESPAÑOLA}

\subsection{Una institución a medio camino entre los Derechos administrativo y mercantil}

La destacada relevancia que esta modalidad de gestión de servicios públicos juega en la esfera local contrasta paradójicamente con la escasa atención

mixtas la encontramos en la Ley Municipal Catalana de 1933-1934 (art. 188) y, poco después, en la Ley Municipal Republicana de 1935 (art. 135). Sin embargo, no se lleva a cabo una regulación detallada de las mismas hasta el Texto Articulado de Régimen Local de 24 de junio de 1955 y el Reglamento de Servicios de las Corporaciones Locales de 17 de junio de 1955.

2 La acción mutua Estado-sociedad de la que habla el Tribunal Constitucional (entre otras, SSTC de 16 de marzo y 18 de abril de 1981 y 7 de febrero de 1984) tiene también su reflejo en el sector económico, donde lo público y lo privado se encuentra mutuamente interrelacionado, esto es, sujeto a reciprocos procesos de coordinación (J. ORTIZ DiAZ, «Problemas estructurales del Derecho de la Organización administrativa", en Revista de Estudios de la Vida Local, REVL n. ${ }^{\circ} 170,1971$, pág. 210 ; A. Alonso Ureba, La Empresa Pública. Aspectos juridicos-constitucionales y de Derecho Económico, Madrid, 1985, págs. 63 y 68; E. Malaret I Garcia, Público y Privado en la Organización de los Juegos Olimpicos de Barcelona 1992, Civitas, Madrid, 1993). No muy lejos de estas coordenadas, AlBı definia la empresa mixta local como «un modo de gestión, en forma de sociedad mercantil, en cuyos capitales y dirección cooperan la Administración y los particulares para realizar finalidades económicas de la Administración) (F. ALBI, Tratado de los modos de gestión de las Corporaciones Locales, Madrid, 1960, pág. 398).

3 En relación con sus posibles inconvenientes, véase las observaciones críticas recogidas en $R$. PARAda Vazquez, Derecho Administrativo, T. II, 7. ed., Marcial Pons, Madrid, 1993, pág. 262. 
EL DOBLE PAPEL DE LA ADMINISTRACIÓN PÚBLICA...

que le dedica nuestra legislación local, anterior y posterior a la Constitución de 1978. Con la excepción de una fugaz referencia en el artículo 85.4, apartado e) de la Ley 7/1985, de 2 de abril, Reguladora de las Bases de Régimen Local (LRBRL), y de los artículos 104 y 105 del Real Decreto Legislativo 781/1986, de 18 de abril, por el que se aprueba el Texto Refundido de disposiciones legales vigentes en materia de Régimen Local (TRRL), su régimen jurídico es el que viene determinado en el Reglamento de Servicios de las Corporaciones Locales de 17 de junio de 1955 (RSCL, arts. 102 a 112), en la medida que no se vean afectados por disposición derogatoria de los textos anteriores ${ }^{4}$.

Esta misma despreocupación se aprecia en la doctrina científica, que en los últimos años tampoco ha prestado la debida atención a la empresa mixta local (a diferencia de lo que sucede en la esfera estatal). Si exceptuamos las publicaciones aparecidas entre los años cuarenta y sesenta, como son la monografia de GIRÓN TENA, entre los mercantilistas, y los trabajos de ClAVERO y ALBI, entre los iuspublicistas ${ }^{5}$, muy poco se ha escrito sobre el tema hasta la fecha y, casi siempre, como parte de obras más genéricas, cuyas referencias concretas aparecerán a lo largo del presente trabajo.

Quizá la respuesta haya de encontrarse en la configuración de estas sociedades como una institución que se sitúa a medio camino entre dos disciplinas tan alejadas como son el Derecho administrativo y el Derecho mercantil, según acredita la distinta procedencia de los autores citados. Singularidad, la comentada, que erige a las sociedades de economía mixta en una de las técnicas de «huida hacia el Derecho privado», tan en boga últimamente, y con lo que se hace referencia a la utilización instrumental por parte de las Administraciones públicas —en el presente caso, de la Administración local- del Derecho privado, con la finalidad de agilizar la funcionalidad de los servicios públicos de carácter mercantil e industrial, liberándolos de las trabas que impone la legislación administrativa (como apunta la STS de 8 de noviembre de 1982, Ref. Ar. 7243); lo que ha de lograrse, eso sí, sin merma del sistema de garantía de los usuarios ${ }^{6}$.

4 Con la excepción, también, de su consagración en las leyes autonómicas de Régimen Local de Cataluña, Ley 8/1987, de 15 de abril (arts. 247-249), y Navarra, Ley Foral 6/1990, de 2 de julio (arts. 198 y 204-211).

5 La obra de Girón Tena a la que nos referimos es Las Sociedades de Economia Mixta, Madrid, 1942. Junto a ésta, se encuentran los trabajos de Clavero ARÉVAlo, especialmente, Municipalización y provincialización de servicios en la Ley de Régimen Local, 1." ed., Madrid, 1952; y ALBI, en particular su ya citado Tratado de los Modos de Gestión de las Corporaciones Locales, 1.a ed., Madrid, 1960.

6 La utilización instrumental del Derecho privado resulta de indudable utilidad para las Administraciones, si bien no podemos desconocer que esta técnica puede lesionar gravemente los derechos de los 
Sin detenernos en esta problemática, que nos alejaría de nuestro objetivo inmediato, creemos oportuno aclarar que esta utilización del Derecho privado no es, ni mucho menos, arbitraria, pues no sólo cuenta con la habilitación legal especifica contenida en los artículos 85 , párrafos $2 .^{\circ}$ y $4 .^{\circ}$, LRBRL y 95 TRRL, sino que ha de seguir, igualmente, un procedimiento administrativo previo a través del cual se concrete el modo gestor y se establezcan las condiciones de participación del Ente público, en los términos que señalan los artículos 104 y 105 del mencionado Texto Refundido.

Con todo, y pese a la evidente descoordinación de los textos legales mercantiles y administrativos, el régimen jurídico de estas sociedades - como veremos a continuación - se adecúa básicamente al Derecho de sociedades, a excepción de unas mínimas especialidades recogidas en la normativa local, que vienen determinadas por la vinculación de su objeto social con una finalidad de utilidad pública (art. 104.2 TRRL).

\subsection{La nueva configuración constitucional de la empresa mixta local: empresas de mercado y empresas de servicio público}

De acuerdo con nuestro Derecho pusitivo, la doctrina española ha concebido tradicionalmente a las empresas mixtas locales como un «modo geston» de los servicios públicos, cuyas peculiares características se determinaban en función de los intereses públicos gestionados ${ }^{\text {? }}$.

usuarios, en cuanto signifique una reducción del sistema de garantías propio del Derecho administrativo, como bien pone de manifiesto la doctrina más reciente. Con carácter general, véase: J. M. SAla ARQUER, «Huida al Derecho Privado y huida del Derecho", en Revista Española de Derecho Administrativo, REDA n. ${ }^{\circ} 75$, 1992, págs. 399-413; I. BORRAJo INIESTA, «EI intento de huir del Derecho Administrativo», en REDA n. 78 , 1993, págs. 233-249; S. DEL SAZ, «La huida del Derecho Administrativo: ültimas manifestaciones. Aplausos y criticas", en Revista de Administración Pública, RAP n. ${ }^{\circ} 133,1994$, págs. 57-98; J .C. LAGUNA DE PAZ, «La renuncia de la Administración pública al Derecho Administrativo», en $R A P$ n. $.^{\circ} 136,1995$, págs. 201-229; F. J. VuLAR Rojas, «La huida al Derecho privado en la gestión de los servicios de salud", en Derecho y Salud, n. 2-2, 1994, págs. 98-106; además de los trabajos publicados en el Libro Homenaje a Clavero Arévalo, Civitas/Garcia Oviedo, Madrid, 1994, págs. 27 a 45, 151 a 184, y 1.015 a 1.067. Sobre el tema que nos ocupa, F. SOSA WAGNER, La gestión de los Servicios Públicos Locales, 1." ed., Civitas, Madrid, 1992, págs. 66-69 y 147-167.

7 Tanto la Ley Reguladora de las Bases de Régimen Local de 1985 (art. 85.3, apartado e), como el Texto Refundido de las disposiciones legales vigentes en materia de Régimen Local de 1986 (especialmente, arts. 104 y 105) y el Reglamento de Servicios de las Corporaciones Locales de 1955 configuran la empresa mixta como una forma típica de gestión de los servicios públicos locales. También es éste el tenor del articulo 157 de la Ley de Contratos de las Administraciones Públicas, de 18 de mayo de 1995 (en la misma línea del art. 66 LCE de 1965). Tan sólo la Ley Catalana 8/1987, de 15 de abril, parece acoger, aunque tímidamente, nuevas posibilidades, al hablar de gestion de «servicios de naturaleza económica», como objeto de las sociedades mercantiles de economia mixta (art. 247). 
En esta línea, tres elementos esenciales conformaban la noción de empresa mixta local: a) la coparticipación financiera de personas jurídico-públicas y jurídico-privadas; b) la colaboración en la administración o gestión de la empresa; y c) la voluntad expresa de la Administración de gestionar, mediante esta forma de sociedad mercantil, una actividad de interés general, lo que le confería el carácter de modo de gestión de un servicio público ${ }^{8}$.

Pero esta concepción tradicional de la empresa mixta local requiere ser revisada a la luz de los nuevos parámetros constitucionales sobre la intervención de las Administraciones Públicas en la economía. De acuerdo con éstos, las Entidades locales ya no se limitan al papel de mero gestor de un conjunto de servicios mínimos, sino que persiguen sobre todo la finalidad de usatisfacer las necesidades y aspiraciones de la comunidad vecinal» (art. 25.1 LRBRL), para lo cual podrán incluso «ejercer la iniciativa pública para el ejercicio de actividades económicas conforme al artículo 128.2 de la Constitución» (art. 86.1 LRBRL); y que viene referida a cualquier tipo de actividad que «sea de utilidad públican, como se encarga de precisar el artículo 96 TRRL, previo el oportuno «expediente acreditativo de la conveniencia y oportunidad de la medidon,, en función del interés público concurrente. En otros términos, cualquiera que sea la actividad que se realice, ésta debe responder siempre, en mayor o menor medida, a una finalidad de interés público ${ }^{9}$.

Desde esta perspectiva, la empresa mixta local, configurada legalmente como un modo de gestión de los servicios locales (de acuerdo con su concepción histórica) puede y debe ser, también, un instrumento de penetración en aquellos sectores que, sin tener la consideración formal de servicio público, suponen el ejercicio de la iniciativa pública local en la actividad económica para participar en la realización de un interés general ${ }^{10}$.

8 Véase al respecto la definición de ALBI, más atrás citada. En esta misma linea, A. GALLGo BuriN, Servicios de las Entidades locales, 1952, T. II, págs. 130 y ss.; M. Clavero ArÉvalo, Municipalización..., ob. cit., págs. 187; y C. ABELLÁN, Tratado práctico de la Administración Local Española, T. III, Madrid, 1971, págs. 835 y ss.

9 En nuestra opinión, el elemento finalista es el determinante principal en la caracterización de esta peculiar forma social, de tal forma que para hablar con propiedad de empresa mixta, la colaboración del Ente local en el capital y gestión de una empresa privada, debe venir acompañada necesariamente de la precisa finalidad de intervenir en la gestión de un servicio público o en la realización de cualesquiera otras prestaciones de interés general. Lo que no sucede, por ejemplo, en aquellas empresas participadas por las Entidades locales como consecuencia de la obligación que el articulo 10.3 del Reglamento estatal de Casinos de Juego, aprobado por Decreto de 9 de enero de 1979, impone a las Sociedades titulares de tales establecimientos de ofertar la participación mayoritaria de su capital social a los Ayuntamientos en cuyo municipio se encuentren ubicados (una critica a este precepto en F. L. HERNÁNDEZ GonZÁLEZ, La regulación de los juegos de azar, Tecnos, Madrid, 1996, págs. 188 y 190).

10 Doble consideración de la empresa mixta, como modalidad gestora de servicios públicos y vía de penetración en actividades económicas privadas, que ha sido apuntada previamente por F. GARRIDO FA- 
Esta consideración obliga a realizar, asimismo, una doble advertencia. En primer lugar, la participación de las Entidades locales en lo que podemos llamar sociedades de mercado, es decir, aquellas que tienen por objeto la realización de actividades económicas, debe respetar no sólo la esfera propia de la competencia local, sino también el conjunto de condiciones, presupuestos y limites - materiales y formales- que imponen tanto la legislación ordinaria (en especial, art. 97.1 TRRL), como la misma legislación comunitaria (en este sentido, la STS de 28 de abril de 1987, Ref. Ar. 4499) ${ }^{11}$. Y, en segundo lugar, la mayor o menor vinculación del objeto social con una finalidad de servicio público determinará, frecuentemente, la atribución de potestades al Ente público socio y las derogaciones singulares del Derecho común que exija la realización del fin público considerado, como veremos más adelante.

\section{EL CARÁCTER INSTRUMENTAL DE LA EMPRESA MIXTA}

Pese a su escaso tratamiento doctrinal, son numerosos los posicionamientos sobre la naturaleza jurídica de la empresa mixta local en nuestro país: desde aquellos que sostienen su exclusiva consideración como persona moral de Derecho privado (tal es el caso de algunos mercantilistas como VICENTEY GelLA, LANGLE o URIA); hasta aquellos otros que mantuvieron su naturaleza puramente administrativa (como fueron GASCón y MARÍN y GA. LLEGO BURIN); hasta la tesis mayoritaria que defienden una posición intermedia, como sociedades formalmente mercantiles pero que ostentan un régimen especial o sui generis (entre los publicistas, ABELLÁN, GARRIDO Falla, García-Trevijano o, entre los mercantilistas, Girón Tena y Broseta PONS).

Frente a estas posturas, compartimos la opinión de autores más recientes que rechazan pronunciarse en términos generales y de un modo dogmático sobre tan compleja cuestión, evitando hablar apriorísticamente y de forma categórica de la naturaleza pública o privada de la empresa mixta. En esta línea,

LLA, Tratado de Derecho Administrativo, T. II, Tecnos, 9. ed., Madrid, 1989, págs. 352-353; y por A. Alonso Ureba, La Sociedad Mercantil de Capital como forma de la Empresa Pública Local, Madrid, 1988, págs. 68 y ss. Hecha esta precisión se hace necesario distinguir inmediatamente entre la finalidad - como causa - de la empresa mixta (siempre dirigida al interés público), verificable en la fase jurídico-administrativa previa a la constitución de la sociedad, y el objeto social, que es el medio para lograr aquélla, cuyo enjuiciamiento se realizará conforme a criterios jurídico-mercantiles, ajenos a la jurisdicción contenciosa (véase, al respecto, la errónea identificación que de ambos extremos hace la STS de 10 de octubre de 1989, Ref. Ar. 7352).

11 Sobre el particular, puede verse L. F. PrIETo GonzÁlez, Las empresas mixtas locales; Montecorvo, Madrid, 1996, pág. 45. 
EL DOBLE PAPEL DE LA ADMINISTRACIÓN PÚBLICA...

seguida más de cerca por AlONSOUREBA ${ }^{12}$, es necesario acudir, una vez más, a la distinción anunciada entre sociedades mixtas de carácter puramente industrial o comercial (sociedades de mercado) y sociedades mixtas de servicio público.

Desde el primer punto de vista, las que denominamos sociedades de mercado, la empresa mixta local no pasa de ser una sociedad de Derecho privado, a través de la cual, las Entidades locales pueden perseguir simplemente una determinada utilidad pública de naturaleza económica ${ }^{3}$. El papel del Ente local se limita, en este caso, a la defensa de sus intereses patrimoniales desde su posición de socio, desprovisto de cualquier tipo de potestades administrativas y utilizando sólo su capacidad como persona jurídico privada ${ }^{14}$, aunque sin posibilidad de sustraerse - como depositario y gestor de los intereses públicos- a los principios constitucionales que rigen la actividad de la Administración.

La situación varía, en cambio, cuando se trata de la sociedad de servicio público, donde la forma mixta presenta un carácter puramente instrumental con respecto a la finalidad concreta de gestión de las prestaciones públicas, con el único objetivo de «agilizar la funcionalidad de ciertos servicios, liberándolos de las rigideces de los principios presupuestarios, de los métodos selectivos del personal y de las trabas del procedimiento administrativon, como sostiene la ya mencionada STS de 8 de noviembre de 1982 (Ref. Ar. 7243).

En todo caso, queda claro que previamente a la participación de la Entidad local en una sociedad mercantil, encontramos siempre una decisión administrativa, a la que se llega a través del correspondiente procedimiento, y que permite desentrañar — en palabras de Tomás Ramón FERNÁNDEZ- «un múcleo insoslayable perteneciente al Derecho Público, perfectamente separable, en cuanto a su tratamiento, del bloque negocial») ${ }^{15}$, que garantice la consecución

12 A. Alonso Ureba, La Sociedad Mercantil de Capital como forma de la Empresa Pública Local, Madrid, 1988, págs. 124 y ss. y 205 y ss.

13 Sobre la utilización estratégica de los patrimonios públicos, J. M. DE LA CuÉtara MARTínEz, La actividad de la Administración, Tecnos, Madrid, 1982, págs. 507 y ss.

14 Por ello mismo, estimamos que la constitución de una empresa mixta de mercado mediante adquisición de acciones o participaciones de una sociedad mercantil ya existente no obliga a modificar, necesariamente, los Estatutos de la sociedad participada, en cuanto el «expediente de conveniencia y oportunidad de la medidan (art. 86.1 LRBRL) no constituye titulo juridico suficiente para alterar las situaciones juridicas preexistentes en dicha sociedad, cuestión que queda deferida, en cualquier caso, al órgano social competente (Junta General de Accionistas).

Is E. Garcia de Enterria y T. R. Fernández Rodriguez, Curso de Derecho Administrativo, T. I, 5 . $^{\circ}$ ed., Civitas, Madrid, 1989, págs. 46-48 y 54. En realidad, estamos ante dos procedimientos administrativos distintos, que responden a diferentes contenidos y finalidades: de un lado, mediante el expediente conveniencia u oportunidad de la medida (art. 97.1,b TRRL) la Entidad local asume una determinada ac- 
de la finalidad pública perseguida; de manera análoga a lo que sucede con la «teoria de los actos separables» en la contratación administrativa y con la «teoria del doble nivel» propia de las técnicas de fomento.

Así lo resalta, por lo demás, la STS de 20 de junio de 1986 (Ref. Ar. 4743), cuando sostiene que «todo servicio público, en cuanto implica una actividad prestacionista del Estado u otro ente público, dirigida a proporcionar una utilidad a los particulares, sólo puede tener como titular activo a dichos entes públicos y esta titularidad es claro que incluye, entre sus facultades, la de desarrollar, llevar a efecto, en definitiva gestionar, el correspondiente servicio, titularidad de gestión de la que, como de la propia titularidad del servicio, no puede desprenderse la Administración, sin que la misma pierda su carácter, lo cual no impide que la gestión pueda desarrollarse de forma directa, indirecta o mixta, ya que, en todo caso, la Administración conserva dicha titularidad de gestión (...) de tal manera que aun cuando se dé entrada a los particulares, a través de las distintas formas legalmente admitidas, a la prestación del servicio, subsiste en la Administración un poder de control y dirección, inherente a su propia titularidad, que ejerce directamente sobre la gestión) ${ }^{16}$.

\section{EL CARÁCTER BIFRONTE DE LA ENTIDẢD LOCAL EN LA SOCIEDAD DE ECONOMÍA MIXTA}

A partir de la materialización de esta previa decisión de carácter público, la Entidad local asume su participación en una empresa mixta, bien mediante la constitución ex novo de la misma, bien mediante la participación en una sociedad preexistente. En este momento, la Entidad local pasa a desempeñar un papel bifronte en la Sociedad, derivado de su doble condición de: a) socio, formando parte integrante de la empresa y sometido, por consiguiente, a la disciplina jurídico-mercantil por la que se rigen las relaciones intrasocietarias; $y$ b) poder público, titular de la competencia de los servicios gestionados y depositaria y garante de los intereses generales.

Como se puede imaginar, esta peculiar posición origina un entramado de relaciones jurídicas entre la Administración local y la empresa participada,

tividad económica en ejercicio de la potestad de iniciativa pública constitucional y legalmente reconocida (arts. $128 \mathrm{CE}$ y $86.2 \mathrm{LRBRL}$ ); y, de otro lado, mediante el ejercicio de la potestad de autoorganización (arts. 4.1,a LRBRL, 95 TRRL y $30 \mathrm{RSCL}$ ), dispone lo más adecuado para la correcta organización y funcionamiento del servicio, dentro del respeto de la legalidad, la competencia material y la conveniente gestión de los intereses generales.

16 Aunque sin esa claridad expositiva, también SSTS de 24 de marzo y 29 de diciembre de 1987 (RR.AA. 3802 y 9855 ). 
unas de carácter interno, derivadas de su condición de socio, y otras de carácter externo, en cuanto entidades jurídicas independientes entre sí que pueden converger en el tráfico jurídico ordinario ${ }^{17}$.

El problema se torna especialmente conflictivo en lo que afecta a las relaciones extrasocietarias, esto es, aquéllas en las que la Entidad local aparece como tercero ante la sociedad mixta, y, más aún, respecto de aquellas sociedades que tienen por objeto la gestión de un servicio público ${ }^{18}$. En este aspecto, ni el Reglamento de Servicios de 1952, ni la Ley de Bases o el Texto Refundido de Régimen Local ofrecen solución alguna.

Tampoco la jurisprudencia aporta una construcción plenamente satisfactoria. Así, por ejemplo, la STS de 24 de marzo de 1987 (Ref. Ar. 3802) distingue entre «la actividad de gestión del servicio público, integramente sometida al Derecho Administrativo, y el régimen interno de la empresa, que lo está a las normas estatutarias». Más específicamente, la STS de 20 de junio de 1986 (Ref. Ar. 4743) precisa que si bien es cierto que la constitución de una empresa mixta supone la creación de una nueva persona jurídica, no por ello se trasladan a ella las potestades administrativas inherentes a la titularidad del servicio (dirección y control, potestad tarifaria, potestad disciplinaria, etc.), de las que en ningún caso puede desprenderse la Administración.

Tan sólo el artículo 206 del Reglamento de Contratos del Estado de 1975 - vigente tras la LCE de 1995, en la medida que no se opone a la mismaprecisa que la empresa mixta «deberá aparecer como parte contratante (...)

17 La distinción entre Estado-poder público y Estado-propietario opera también en el ámbito del Derecho Comunitario a efectos del control de las ayudas públicas del articulo 92 TCEE, en especial de aquellas que se materializan a través de la participación de las autoridades públicas en el capital social de las empresas. Asi lo establece la Directiva de la Comisión de 23 de junio de 1980, relativa a la transparencia de las relaciones financieras entre Estados miembros y empresas públicas (DO 9/94). Al respecto, pueden consultarse las Sentencias del TJCEE de 10 de julio de 1986 (As. C 234/84 y 40/85), entre otras muchas, $y$, en la doctrina, A. PAPPALARDO, "Les participations de l'Etat dans le capital d'enterprises constituent-elles des aides au sens de l'article 92 du Traité CEE?», en Documentaçao e Direito Comparado, Lisboa, 1988; también citado por A. Matiera, El Mercado Único Europeo. Sus reglas. Su funcionamiento, Civitas, Madrid, 1991, págs. 90-93; C. F. Mol.INA DEL Pozo, «La empresa pública y el Derecho comunitario: Especial referencia a los limites establecidos para las ayudas por la normativa comunitaria", en Revista de estudios e investigación de las Comunidades Europeas, n. ${ }^{\circ} 23-24,1991$, en especial, págs. 560-563; y G. FERNÁNDEZ FARRERES, El Régimen de las Ayudas estatales en la Comunidad Europea, Cuadernos de Estudios Europeos, Civitas, Madrid, 1993.

18 Ninguna dificultad plantean las relaciones intrasocietarias, en la medida que quedan básicamente sujetas a la legislación mercantil (por todas, SSTS de 8 de noviembre de 1982, Ref. Ar. 7243; y 24 de marzo de 1987, Ref. Ar. 3802). Por su parte, tampoco las relaciones extrasocietarias que puedan entablarse entre la Entidad local y la empresa mixta de mercado en que participa plantean otras peculiaridades dignas de resaltar, que no sea el mayor contacto que la Administración local pueda tener con éstas (en relación a cualquier otra sociedad), en consideración a su mayor convergencia en cuanto a los intereses generales. 
con las obligaciones y derechos propios del concesionario de servicios públicos»; lo que va a ser fundamental, por ejemplo, a efectos de responsabilidad extracontractual de la sociedad, en cuanto gestora de servicios públicos.

Sin embargo, esta afirmación inicial requiere ser matizada. Es cierto que en toda gestión indirecta se establece un vínculo Administración-Gestor. El problema es que mientras que en esas otras formas de gestión que son la concesión, el arrendamiento, la gestión interesada, etc., la personalidad jurídica del gestor es ajena a la Administración y preexistente a dicho vínculo, que se establece por vía contractual; en la empresa mixta, la Administración participa en la génesis de la personalidad gestora y asume, directamente, una parte alícuota del riesgo y de la responsabilidad de la gestión.

Ahora bien, no por ello, la simple participación del Ente local en una sociedad mercantil habilita a la misma para la gestión de un servicio o prestación pública. Como señala DE LA CUÉTARA, el vínculo jurídico-privado no es suficiente, sino que será necesaria una investidura, un vínculo específico adicional, teniendo en cuenta la «triple relación Administración-empresa-usuario en la que es necesario equilibrar los títulos respectivos de cada sujeto, conforme a las reglas del Derecho público»" ${ }^{19}$. Esta última circunstancia nos lleva, indudablemente, al planteamiento de un doble vínculo relacional:

a) Un vínculo estrictamente jurídico-privado, que se formaliza a través del contrato de sociedad y del que deriva la posición jurídica de la Entidad local como socio, con los derechos y deberes inherentes a tal condición y, por consiguiente, carente de facultades exorbitantes derivadas de sus potestades públicas.

b) Un vínculo adicional, de carácter público, que se formalizará, bien directamente en el propio contrato societario, bien mediante la incorporación al mismo del Estatuto del Servicio público o, en su caso, a través de un muevo contrato distinto del mercantil, como ya ha ocurrido en el sector estatal (Transmediterránea, Tabacalera, etc.).

Desde este particular enfoque, debemos distinguir entre las actividades directamente relacionadas con el ejercicio de potestades derivadas de la titularidad pública del servicio, que constituyen el núcleo indisponible de dicha titularidad; y aquellas otras que, pudiendo estar relacionadas con la prestación del servicio, constituyen el giro o tráfico normal de la empresa y que ésta realiza con absoluta libertad de decisión. Pues bien, sobre las primeras, la Administración ejerce un control ex-

19 J. M. DE LA CUÉtARA MARTinez, «Título habilitante de las empresas $100 \%$ propias de un ente público para la gestión de servicios públicos», en Libro Homenaje al Prof. Clavero Arévalo, T. II, Madrid, 1994, págs. 1.091-1.100. 
EL DOBLE PAPEL DE LA ADMINISTRACIÓN PÚBLICA...

terno, propio de las relaciones de tutela; mientras que en la toma de decisiones relacionadas con la actividad de la misma no vinculada directamente a la prestación del servicio público, el Ente local únicamente podrá intervenir en su calidad de socio, a través de su participación en los órganos de administración de la sociedad.

En definitiva, la solución pasa necesariamente por una exteriorización contractual de las relaciones que afectan especificamente al servicio público, que permitirá someter dichas relaciones a una disciplina jurídico-pública perfectamente diferenciada y resolver otros problemas que plantea la participación pública en la empresa mixta, como son, por ejemplo: la posible aportación del aprovechamiento de bienes demaniales, soporte del servicio público gestionado; el régimen de responsabilidad extracontractual derivada del funcionamiento del servicio; la obligación de la Entidad local de corregir los posibles desequilibrios económicos consecuencia de la política tarifaria de la propia Corporación; el ejercicio de determinadas facultades de control público sobre las actividades de la Empresa; o, finalmente, el régimen de reversión de los bienes afectados al servicio público a la disolución de la sociedad ${ }^{20}$.

\section{LA ESPECIAL POSICIÓN DEL SOCIO PÚBLICO}

Uno de los problemas fundamentales que plantea el régimen jurídico de las sociedades locales de economía mixta es el grado de intervención del socio público en relación con su aportación económica, y si esta posición puede verse eventualmente reforzada mediante el establecimiento de determinadas especialidades internas, tanto orgánicas como funcionales, que alteren de algún modo el status jurídico-mercantil de la institución.

\subsection{La tutela del interés público como determinante de la incorporación de especialidades al régimen mercantil}

Tradicionalmente, la doctrina administrativista ha justificado una posible situación de preeminencia del socio público en la empresa mixta, tomando como argumento la necesidad de defensa de los intereses generales que aquél representa (por encima de sus propios intereses económicos), sin necesidad de responder siempre al criterio mercantil de estricta proporcionalidad ${ }^{21}$.

20 Temas todos ellos abordados, con profundidad, en L. F. Prieto González, Las empresas mixtas..., ob. cit., págs. $77-92$ y 175-252.

21 Así, principalmente en la doctrina francesa, A. CHÉRON, De l'actionnariat des collectivités publiques, 
A diferencia de lo que sucede en las sociedades con participación pública estatal, en el Derecho local ha sido la normativa general la que ha venido considerando siempre la existencia de determinadas especialidades en el régimen jurídico-mercantil de las sociedades mixtas. Desarrollando las previsiones de la Ley de Régimen Local de 1955, el Reglamento de Servicios de las Corporaciones Locales consagró diferentes singularidades, si bien carentes de una disposición de propósito general vertebradora de todo el sistema, así como de referencias importantes (tales como el derecho de veto, las facultades de los representantes del socio público o las mismas relaciones con la Entidad local, entre otras). A saber, aquellas especialidades se concretan en:

a) la posibilidad de que el número de votos de la Corporación pueda ser inferior a la proporción del capital con que participare en la empresa, salvo en los cinco años anteriores al término de la misma, en que deberá ser igual o superior (art. 106.1) ${ }^{22}$;

b) la institucionalización de la Gerencia (art. 106.3);

c) el establecimiento de un quórum especial (mayoría de tres cuartas partes del número estatutario de votos) para la adopción de determinados acuerdos (art. 107); y

d) la libre designación y remoción de los representantes municipales en los órganos de gobierno y administración de la empresa mixta, con el único límite de que el $50 \%$ de los designados serán miembros de la Corporación y el 50\% restante, personal técnico (art. 108).

El Texto Refundido de Régimen Local de 1986 mejoró la situación: de un lado, al incorporar en el artículo 104.2 aquella disposición general -ausente en el RSCL_, según la cual «en el acuerdo constitutivo podrán establecerse las especialidades internas tanto estructurales como funcionales que, sin perjuicio de terceros, exceptuen la legislación societaria aplicable en la medida necesaria para promover y desarrollar la empresa mixta de carácter mercantil o cooperativon; $\mathrm{y}$, de otro lado, porque al margen de la crítica

\footnotetext{
París, 1928, pág. 35; R. Bonnard, Précis de Droit Administratif, Paris, 1943, pág. 708; entre otros. En nuestro pais, también lo destaca F. AlB1, Tratado de los Modos de Gestión..., ob. cit., pág. 406 y, más recientemente, F. SOSA WAGNER, La gestión de los servicios..., ob. cit., págs. 159-160.

22 Singularidad ésta que no fue bien acogida por la doctrina, que la tachó de «inadmisible y absurdan) (F. AlBI, Tratado de los Modos de Gestión..., ob. cil., pág. 407); y cuya justificación, sitủa ABE. LLÁN, en la "desconfianza que en el capital privado pueda producir el quedar sometido al criterio de la Corporación que, en negocios privados, suele ser menos eficaz que el de los particulares》) (C. ABELLȦN, Tratado práctico..., T. III, ob. cit., pág. 846).
} 
E. DOBLE PAPEL DE LA ADMINISTRACIÓN PÚBLICA..

que merezca su tenor literal ${ }^{23}$, lo cierto es que el artículo 104.2 TRRL intenta determinar, con mayor o menor fortuna, el alcance y los límites a la derogabilidad del Derecho común de sociedades en las empresas con participación pública local.

La susodicha disposición permite una cierta libertad organizativa, coherente con la potestad reglamentaria y de autoorganización de los Entes Locales (art. 4.1,a LRBRL) y que viene a desempeñar un papel equivalente al que juega el principio general de respeto a la autonomía de la voluntad en Derecho societario (art. 10 LSA y $115.2 \mathrm{RRM}$ ). Se trata, con todo, de una discrecionalidad relativa, cuyo ejercicio ha de ser proporcional al contenido público de la actividad de la empresa y, naturalmente, fiscalizable ante los tribunales de lo contencioso-administrativo.

En cualquier caso, la referencia del artículo 104.2 TRRL permitirá salvar, mediante su plasmación en el acuerdo constitutivo, el establecimiento de algunas de las peculiaridades recogidas en el RSCL —más atrás expuestas - que contrastan frontalmente con la legislación mercantil (posterior y superior en el rango, lo que lleva a algún sector doctrinal a cuestionarlas), a condición de que sean necesarias para la consecución del interés público concurrente y no alteren las relaciones juridicas extrasocietarias, en perjuicio de terceros, de acuerdo con el esquema propio de la normativa societaria. Así sucede con la posibilidad de «acciones de voto pluralis (art. 106.1 RSCL), contraria al principio de proporcionalidad entre el valor nominal de la acción y el derecho de voto que establece al artículo 50.2 LSA; o con la libre designación de los representantes municipales (art. $108 \mathrm{RSCL}$ ), que colisiona con la facultad que el art. 123.1 LSA atribuye a la Junta General de Accionistas ${ }^{24}$.

Ahora bien, frente a cualquier situación generalizada de privilegio del socio público se hace necesario tener presente dos premisas fundamentales, ya destacadas por la doctrina:

En primer lugar, que la posición preeminente del socio público sólo se justifica - $\mathrm{e}$ incluso requiere ser reforzada - en la medida en que lo exija la ade-

${ }^{23}$ Su párrafo final no puede ser más desafortunado: la atribución y el ejercicio de potestades administrativas sólo se justifica cuando está en juego la consecución de una finalidad pública; tal como está redactado el mencionado precepto, parece que la finalidad de las especialidades internas que exceptúen la legislación societaria fuesen la promoción y el desarrollo de la empresa, cuando en realidad la empresa no es sino un instrumento para la finalidad de gestión del servicio público (sobre el alcance y límites de esta facultad de excepcionar el régimen jurídico-mercantil, G. ALCOVER GARAU, «Aproximación al régimen jurídico de la Sociedad de capital local», en RAP n. ${ }^{\circ} 134,1994$, en especial, págs. 87-89, 95 y 105-106).

Véase con más detalle, L. F. Prieto GonzÁlez, Las empresas mixtas..., ob. cit., págs. 157-160. 
cuada protección de los intereses generales custodiados por el mismo y que ha motivado la participación pública en la empresa ${ }^{25}$.

En segundo lugar, que el planteamiento de base sobre el que se asienta esta peculiar posición del socio público pasa por diferenciar, una vez más, entre empresa de servicio público y empresa de mercado, resultando la mayor o menor vinculación del objeto social con la finalidad precisa de gestionar un servicio de interés general, lo que determina la posibilidad, la oportunidad y el alcance del establecimiento de un régimen jurídico más o menos exorbitante del Derecho común de sociedades ${ }^{26}$.

En conclusión, podemos afirmar, sin ningún tipo de duda, que la sociedad de economía mixta es, fundamentalmente, y pese a su forma de personificación jurídico privada, una entidad instrumental que remite —n último término- su titularidad "a una instancia administrativa inequivocamente pública» (STC de 31 de enero de 1986), por cuenta de la cual sirve, con mayor o menor medida, una finalidad de interés general; siendo esta particular vinculación de su objeto social con una finalidad de interés público (y no la presencia en la misma de un Ente local), la que le confiere un carácter especial y la que va a determinar, en su caso, la necesidad de un cierto control público de estas sociedades, entendido en sentido amplio, en cuanto posibilidad de la Administración de influir de forma decisiva en la vida de la sociedad.

\subsection{El equilibrio interno de la sociedad}

Lo dicho con anterioridad requiere una cautela. Un absoluto predominio del socio público, completamente al margen de su participación en el capital social y de las reglas básicas del Derecho de sociedades, tampoco se presenta como la situación más favorable del funcionamiento de la sociedad; máxime teniendo en cuenta la posible existencia de intereses contrapuestos y finalidades divergentes con el socio privado, que son necesarios unificar para lograr un instrumento de gestión, como nos recuerda ALBI ${ }^{27}$. No podemos olvidar tampoco que la colaboración del sector privado, el riesgo económico asumido por éste y su implicación directa en el éxito del negocio forman parte de la esencia misma de la sociedad mixta y no pueden ni deben quedar relegados a un segundo plano.

25 Asi to ha puesto de relieve, entre otros, el tratadista argentino A. GRECA, Derecho y Ciencia de la Administración municipal, Santa Fe, 1943, pág. 269.

26 Por todos, en nuestra doctrina, A. Alonso Ureba, La Sociedad Mercantil de Capital..., ob. cit., pág. 127; y L. F. PRIETo GonzÁlez, Las empresas mixtas..., ob. cit., en especial, págs. 148-151.

27 F. AlB1, Tratado de los Modos de Gestión..., ob. cit., págs. 391 y 400 y ss. 
E. DOBLE PAPE DE LA ADMINISTRACIÓN PÚBLICA...

Se hace necesario, pues, buscar fórmulas de equilibrio que, con independencia de la participación económica, permitan compatibilizar los diversos intereses que conviven en la empresa mixta, asegurando - a su vez- la adecuada gobernabilidad de la sociedad y la protección suficiente de los intereses públicos gestionados; lo que CLAVERO define como «una combinación ponderada de un conjunto de elementos de hecho (...) el juego de la iniciativa particular frente a la intervención de las Corporaciones públicas, las ganancias de los socios frente a la absorción de las superrentas, la cuantía de la aportación privada frente a la públicas ${ }^{28}$.

Al objeto de alcanzar este equilibrio, el propio ALBI sugiere la utilización, independiente o combinada, de diversos mecanismos jurídicos, tales como: derecho de veto o facultad de suspensión de acuerdos sociales; la necesidad de ratificación posterior de aquéllos; la exigencia de un quórum especial; $y$, finalmente, la constitución de un organismo de inspección de mayoría pública. A éstas pueden añadirse otras técnicas ya conocidas, como son: la mayoría privada en los Consejos de Administración, acompañada de un adecuado control público de la Asamblea General; la designación de Consejeros al margen de la Junta General; el nombramiento de interventores técnicos o, en su caso, de un Delegado o Comisario del Gobierno; etc.

En resumen, debe quedar perfectamente claro que, si bien la garantía del interés público perseguido exige determinadas especialidades de régimen jurídico en las sociedades de economía mixta, la simple participación del socio público no debe suponer un apartamiento respecto al régimen común tan especialmente significativo que impida reconocer en ellas su verdadera naturaleza mercantil. Antes bien, será la feliz combinación de fórmulas de equilibrio entre ambos sectores la mejor garantía de mutuo respeto de los intereses público y privado, que permita el logro del primero, sin riesgos innecesarios para el segundo ${ }^{29}$.

\section{LA ENTIDAD LOCAL EN CUANTO PODER PÚBLICO: EL CONTROL PÚBLICO DE LAS EMPRESAS MIXTAS}

\subsection{Fundamentos y límites de la potestad de control}

Como vimos más atrás, en su condición de garante de los intereses públicos (para lo cual viene investida de potestades administrativas), la Entidad local ejerce un control externo sobre las empresas de economía mixta en las que par-

28 M. F. Clavero ArÉvalo, Municipalización..., ob. cit., pág. 201. En el mismo sentido, C. Abell.áN, Tratado prdctico..., T. III, ob. cit., pág. 846.

29 En idéntico sentido, M. F. Clavero ArÉvalo, Municipalización..., ob. cit., pág. 201. 
ticipa ${ }^{30}$, distinto al mero control interno que en su condición de socio realiza a través de cauces jurídico-mercantiles (art. 115 y ss. LSA). Este control externo puede obedecer a diversas razones:

De un lado, y de modo principal, la necesidad de garantizar el destino de los fondos públicos comprometidos en la empresa. De otro lado, la misma salvaguarda del fin, interés o utilidad pública que debe informar toda la actividad administrativa y que justifica la propia participación pública en una sociedad de esta naturaleza. $\mathrm{Y}$, finalmente, la titularidad del servicio público, que constituye en muchos casos el objeto de las sociedades de economía mixta, permite igualmente un poder de control y dirección inherente a la propia titularidad (como núcleo indisponible de la misma).

No obstante, estas facultades de control están sujetas a tres grandes límites, dos de los cuales son de alcance general y derivan del carácter interventor de la actuación administrativa, y uno - final- está en estrecha vinculación con la naturaleza de la sociedad misma. A saber, éstos son:

a) El principio de legalidad (arts. 103.1 CE y 6.1 LRBRL), que exige norma legal previa que defina el fin, alcance y objetivo de la actuación administrativa.

b) Los principios que rigen la intervención de las Administraciones Públicas en la actividad privada, en especial, los principios de proporcionalidad, congruencia y razonabilidad de la medida con los fines que la justifican (arts. 84.2 LRBRL y 2,4 y 6 RSCL), de tal forma que la intervención será más intensa en las sociedades de gestión de servicio público que en las empresas de mercado, donde el interés general queda reducido, casi exclusivamente, a la participación financiera de la Administración.

c) El respeto de la naturaleza juridica de la sociedad mixta, de tal forma que la oportuna intervención administrativa en defensa del interés general y en la evaluación de su consecución garantice, en todo caso, la imprescindible autonomía que requiere el desarrollo de su actividad empresarial; evitando, de este modo, burocratizar en exceso el funcionamiento de estas empresas, frente a las exclusivamente privadas ${ }^{31}$.

30 Que las empresas de economia mixta están sujetas a controles administrativos no es una afirmación nueva, pero sí necesaria en cuanto un importante sector doctrinal toma este dato como factor determinante - frente a la titularidad— del carácter público de este tipo de sociedades (por todos, R. MARTiN MATEO, y F. SOSA WAGNER, Derecho Administrativo Económico. El Estado y la Empresa, Madrid, 1977, pág. 115; y F. Lliset Borreul, La actividad empresarial de los Entes Locales, Abella, Madrid, 1990, pág. 167; entre otros).

31 En este sentido, también F. LliSet BorRel, La actividad empresarial..., ob. cil., págs. 169-170; A. 
EL DOBLE PAPEL DE LA ADMINISTRACIÓN PÚBLICA..

Un planteamiento de este tipo nos lleva, por ejemplo, a negar la posibilidad de la Entidad local de disolver el vínculo societario, de forma unilateral, utilizando prerrogativas de Derecho público, que la doctrina tradicionalmente viene admitiendo a través del cauce de la "rescisión contractual» (actual art. 108 ,d TRRL) ${ }^{32}$. En este punto, es necesario reconducir el problema, una vez más, a la distinción entre sociedades de mercado y sociedades de servicio público, si bien a los solos efectos de su liquidación. Así, mientras que en ambos tipos de sociedad el procedimiento de disolución habrá de sujetarse, en último término, a la legislación mercantil, es necesario admitir un régimen jurídico específico para la liquidación de aquellas últimas, que garantice la reversión de los bienes afectados al servicio público.

\subsection{Las técnicas de fiscalización administrativa}

Por lo que se refiere a los mecanismos de control administrativo de las empresas mixtas, hemos de establecer una distinción entre aquellos que tienen por objeto la fiscalización preventiva de las actividades de la empresa a fin de encauzar su actividad y aquellos otros que permiten verificar el resultado de la gestión empresarial.

\section{A. Técnicas de control preventivo}

Por lo que a éstos se refiere ${ }^{33}$, la Ley Reguladora de las Haciendas Locales de 28 de diciembre de 1988 (LRHL) recoge los denominados «Programas de

MARTíNEZ, «La empresa pública local en España: un análisis crítico de su situación en el ámbito financiero-presupuestario", en Revista de Estudios de la Administración Local y Autonómica, REALA n. ${ }^{\circ}$ 253, 1992, pág. 35.

32 En esta línea se pronunciaron F. ALBl, Tratado de los Modos de Gestión..., ob. cit., pág. 427; y C. ABEllán, Tratado práctico..., ob. cit., pág. 849 y ss. Más recientemente, F. SOSA WAGNER, La gestión de los servicios..., ob. cit., págs. 166-167; y F. LliSET BORRELl, La actividad empresarial..., ob. cit., pág. 157. Pese a las opiniones de signo opuesto, la disolución unilateral no se puede justificar por la vía de la rescisión contractual del artículo 108,d) TRRL, pues, como mantiene la doctrina mercantilista, el acto constitutivo de la sociedad se agota con su mera creación; lo que no permite hablar de rescisión del contrato. Antes bien, el indicado precepto debe ser reconducido al marco de las relaciones extrasocietarias, esto es, aquellas que vinculan a la sociedad gestora del servicio con la Entidad local en su condición de titular del servicio; posición que avala el artículo 225.1 RCE, al obligar a.la Administración a abonar a la empresa (no al socio privado) el precio de las obras e instalaciones que hubieran de revertir anticipadamente a la Corporación, "teniendo en cuenta su estado y el tiempo que restare para la reversión» (art. 170.1 LCE y 225.1 RCE).

33 No constituye un verdadero mecanismo de control la Reglamentación del servicio, aun cuando en la misma la Corporación determinará, entre otras circunstancias, "las modalidades de prestación, situa. ción, deberes y derechos de los usuarias) (art. 3 RSCL). 
Actuación, Inversiones y Financiación» (PAIF), elaborados por las empresas «de cryo capital social sea titular único o participe mayoritario la Entidad localı y que deberán remitir a la Administración antes del 15 de septiembre de cada año, para ser incorporados como anexo al Presupuesto General de la Corporación respectiva (arts. 147.1 y 149.3).

En nuestra opinión, la limitación normativa a las empresas de capital mayoritariamente público debería completarse con la posibilidad de estatuir la obligatoriedad de tales Programas respecto de aquellas sociedades mixtas en que, sin alcanzar un porcentaje de capital público superior al 50\% - como se interpreta esta participación mayoritaria - ${ }^{34}$, se encuentren fuertemente implicados los intereses públicos, que de otra manera pueden quedar peligrosamente comprometidos.

Por lo demás, el contenido del PAIF -no vinculante para la empresacomprenderá el estado de las inversiones a realizar dentro de cada ejercicio, las fuentes de financiación de tales inversiones (con especial referencia a las aportaciones a recibir de la Entidad local), la relación de objetivos a alcanzar y rentas a generar y la memoria de las actividades a realizar, según determina el artículo 114 del Real Decreto 500/1990, de 20 de julio, que desarrolla la LRHL en materia de contabilidad ${ }^{35}$.

No recogidos en la legislación de ámbito local, pero igualmente predicable respecto de las sociedades mixtas de esta naturaleza que tengan por objeto la gestión de un servicio público, son los denominados "Contrato-programas», que por vez primera incorpora a nuestro ordenamiento jurídico la Ley General Presupuestaria de 1977 (art. 91), respecto de aquellas sociedades que reciban subvenciones con cargo a los Presupuestos del Estado.

El mecanismo del Contrato-programa representa, sobre cualquier otra forma de control preventivo, evidentes ventajas. De un lado, porque se parte de una situación de autonomía jurídica de la sociedad, que se relaciona con la Entidad local, no como dependiente de la misma, sino como parte contratante en un plano de igualdad (aunque cabe reconocer que las necesidades financieras de la empresa pueden mermar profundamente su posición negociadora). De otro lado, porque supone el reconocimiento (valorado y cuantificado en lo posible) de las actividades de interés general gestionadas por la empresa y que justifican la participación fi-

34 En esta línea, F. LLISET BORREL, La actividad empresarial..., ob. cit., pág. 172; F. SOSA WAGNER, La gestión de los servicios..., ob. cit., págs. 165-166; J. SÁNChEz RevengA, La Presupuestación por Objetivos y Programas, Banco de Crédito Local, Madrid, 1990, pág. 120; entre otros.

35 Al respecto, puede consultarse, con mayor detalle, A. MARTiNEz, La empresa puiblica local..., ob. cit., págs. 30 y ss. 
E. DOBLE PAPEZ DE LA ADMINISTRACIÓN PÚBLICA...

nanciera y gestora del Ente local. Y, finalmente, porque permite disponer de elementos objetivos para juzgar la calidad y suficiencia de la gestión empresarial, vinculardo las transferencias públicas a la consecución de los objetivos propuestos.

\section{B. Técnicas de control de la gestión}

Estos instrumentos de control público vienen referidos, casi con exclusividad, a las sociedades cuyo objeto social aparece vinculado a la gestión de un servicio público, y derivan de aquella posición externa de la empresa en relación con la Administración titular del servicio, a la que nos hemos referido más arriba.

En primer lugar, estos controles son los propios de la concesión, pues - como sabemos- el artículo 206 RCE equipara a la sociedad de economía mixta, por lo que a derechos y obligaciones se refiere, a los concesionarios de servicios públicos; precisando, por lo demás, el artículo $200 \mathrm{RCE}$ que la Administración conservará, en todo caso, «los poderes de policia necesarios para asegurar la buena marcha del servicio de que se trate». En su virtud, por aplicación analógica del artículo 121.1.2. ${ }^{\mathrm{a}} \mathrm{RSCL}$, la Entidad local podrá fiscalizar la gestión de la empresa, inspeccionar el servicio, sus obras, instalaciones y locales, así como la documentación relacionada con el objeto de la empresa y dictar las órdenes necesarias para mantener o restablecer la debida prestación ${ }^{36}$.

Dentro del control de la gestión, debemos hacer mención, igualmente, al control financiero, que se realizará «por procedimientos de auditoria de acuerdo con las normas de auditoria del Sector Públicon, de conformidad con el artículo 201 LRHL; y al denominado control de eficacia, entendido en los términos del artículo 202 LRHL, como aquel que tiene por objeto «la comprobación periódica del grado de cumplimiento de los objetivos, asi como el análisis del coste de funcionamiento y del rendimiento de los respectivos servicios o inversiones" ${ }^{37}$. Ambos resultan aplicables a las empresas mixtas locales, como bien admite la doctrina ${ }^{38}$, aunque con un alcance tanto más limitado cuanto menor

36 La competencia orgánica para el ejercicio de dichas potestades de fiscalización y control de la gestión de los servicios públicos corresponde al Presidente de la Corporación o Diputación, respectiva, de conformidad con to que disponen los artículos 21.1,d) y 34.1,d) LRBRL y arts. 41.6 y 61.7 del Reglamento de Organización, Funcionamiento y Régimen Jurídico de las Entidades Locales de 28 de noviembre de 1986 (ROF).

37 Ast se pronuncia también el artículo 17.2 LGP (un desarrollo pormenorizado en F. BOSCH FERRE, El control financiero, Banco de Crédito Local, Madrid, 1991, págs. 29 y ss.; M. CABRERA Pérez-CAMACHO, El control externo de la actividad financiera, Imprenta Bonnet, S/C de Tenerife, 1991.

38 Por todos, F. SOSA WAGNER, La gestión de los servicios..., ob. cit., pág. 66; y A. MARTínez, La empresa priblica local..., ob. cit., pág. 44. 
sea la participación de la Entidad Local y teniendo en cuenta que, a salvo siempre la autonomía de gestión que comporta la personalidad jurídico-mercantil, en la mayo. la de los casos, el resultado de dichos controles determinará únicamente un replanteamiento por parte de la Administración, tanto de su posición en la empresa, como del propio modo de gestión de los servicios.

\section{BIBLIOGRAFÍA}

ABELLÁN, C., Tratado práctico de la Administración Local Española, Madrid, 1971.

ALBI, F., Tratado de los modos de gestión de las Corporaciones Locales, Madrid, 1960.

AlCOVER Garau, G., «Aproximación al régimen jurídico de la Sociedad de capital local», en Revista de Administración Pública, RAP n.. 134, 1994.

A. Alonso Ureba La Empresa Pública. Aspectos juridicos-constitucionales y de Derecho Económico, Madrid, 1985.

Alonso Ureba, A., La Sociedad Mercantil de Capital como forma de la Empresa Pública Local, Madrid, 1988. 1991.

BOsch FerRe, F., El control financiero, Banco de Crédito Local, Madrid,

Bonnard, R., Précis de Droit Administratif, París, 1943.

BorRAJO INIESTA, I.,. «El intento de huir del Derecho Administrativo», en Revista Española de Derecho Administrativo, REDA n. ${ }^{\circ} 78,1993$.

CABRERA PÉREz -CAMACHQ M., El control externo de la actividad financiera, Imprenta Bonnet, S/C de Tenerife, 1991.

Clavero ARÉvalo, M., Municipalización y provincialización de servicios en la Ley de Régimen Local, 1.a ed., Madrid, 1952.

CHÉRON A., De l'actionnariat des collectivités publiques, París, 1928.

Dela Cuétara Martínez, J. M. La actividad de la Administración, Tecnos, Madrid, 1982. 
EL DOBLE PAPEL DE LA ADMINISTRACIÓN PÚBLICA..

Dela Cúttara Martínez, J. M., «Título habilitante de las empresas $100 \%$ propias de un ente público para la gestión de servicios públicos», en Libro Homenaje al Prof. Clavero Arévalo, T. II, Madrid, 1994.

Del SAZ, S., «La huida del Derecho Administrativo: últimas manifestaciones. Aplausos y críticas», en Revista de Administración Pública, RAP n. ${ }^{\circ}$ 133, 1994.

Fernández Farreres, G., El Régimen de las Ayudas estatales en la Comunidad Europea, Cuadernos de Estudios Europeos, Civitas, Madrid, 1993.

Gallego Burín, A., Servicios de las Entidades locales, Madrid, 1952.

García de Enterría, E. y Fernández Rodríguez, T. R. Curso de Derecho Administrativo, T. I, 5. ${ }^{3}$ ed., Civitas, Madrid, 1989.

Garrido Falla, F., Tratado de Derecho Administrativo, Tecnos, 9." ed., Madrid, 1989.

Girón Tena , J., Las Sociedades de Economía Mixta, Madrid, 1942. 1943.

Greca, A., Derecho y Ciencia de la Administración municipal, Santa Fe,

HeRnÁNDEZ González, F. L., La regulación de los juegos de azar, Tecnos, Madrid, 1996.

Laguna de Paz, J. C., «La renuncia de la Administración pública al Derecho Administrativo",, en Revista de Administración Pública, RAP n. ${ }^{\circ} 136$, 1995.

LLISET BORRell, F., La actividad empresarial de los Entes Locales, Abella, Madrid, 1990.

Malaret i García, E., Público y Privado en la Organización de los Juegos Olimpicos de Barcelona 1992, Civitas, Madrid, 1993.

Martin Mateo, R y SOSa Wagner, F., Derecho Administrativo Económico. El Estado y la Empresa, Madrid, 1977.

MARTíneZ, A., «La empresa pública local en España: un análisis crítico de su situación en el ámbito financiero-presupuestario», en Revista de Estudios de la Administración Local y Autonómica, REALA n. ${ }^{\circ} 253,1992$. 
MATTERA, A., El Mercado Único Europeo. Sus reglas. Su funcionamiento, Civitas, Madrid, 1991.

Molinadel Pozo, C. F., «La empresa pública y el Derecho comunitario: Especial referencia a los límites establecidos para las ayudas por la normativa comunitaria», en Revista de estudios e investigación de las Comunidades Europeas $\mathrm{n}^{\circ} 23-24,1991$.

OrTiz Diaz, J., «Problemas estructurales del Derecho de la Organización administrativas, en Revista de Estudios de la Vida Local, REVL n. ${ }^{\circ}$ 170, 1971.

Pappalardo, A., «Les participations de l'Etat dans le capital d'enterprises constituent-elles des aides au sens de l'article 92 du Traité CEE?», en Documentaçao e Direito Comparado, Lisboa, 1988.

Parada VázQuez, R., Derecho Administrativo, T. II, 7. ${ }^{a}$ ed., Marcial Pons, Madrid, 1993.

Prieto González, L. F., Las empresas mixtas locales, Montecorvo, Madrid, 1996.

Sala ArQuer, J. M., «Huida al Derecho Privado y huida del Derecho», en Revista Española de Derecho Administrativo, REDA n. ${ }^{\circ} 75,1992$.

SÁnchez Revenga, J., La Presupuestación por Objetivos y Programas, Banco de Crédito Local, Madrid, 1990.

Sosa Wagner, F., La gestión de los Servicios Públicos Locales, 1.a ed., Civitas, Madrid, 1992.

VV.AA. Libro Homenaje a Clavero Arévalo, Civitas/García Oviedo, Madrid, 1994.

Villar Rojas, F. J., «La huida al Derecho privado en la gestión de los servicios de salud», en Derecho y Salud n. ${ }^{\circ} 2,1994$. 